\title{
常微分方程复定性理论中的基本定理
}

考虑复域中微分方程

$$
\frac{\mathrm{d} W}{\mathrm{~d} T}-F(T, W), \quad W \in C^{m},
$$

其中 $C^{m}$ 表示 $\boldsymbol{m}$ 维复空间, $\boldsymbol{F}: \boldsymbol{C}^{\boldsymbol{m + 1}} \rightarrow \boldsymbol{C}^{\boldsymbol{m}}$ 为 解析函数. 由 Cauchy 定理, 方程 (1) 满足 $T=T_{0}, W-W_{0}$ 的局部解析解存在唯一, 记为 $W=W\left(T ; T_{0}, W_{0}\right),\left|T-T_{0}\right|<r(r>$ $0)$, 以它为解析函数元素进行解析开拓, 得 到一个整体解析函数 $\Phi\left(T ; T_{0}, W_{0}\right)$, 其定 义域为 $\mathrm{D}\left(T_{0}, W_{0}\right)$. 可以证明 $\mathrm{D}\left(T_{0}, W_{0}\right)$ 为 $C^{1}$ 中开集. 如果 $\Phi\left(T ; T_{0}, W_{0}\right)$ 可沿 弧线 $L$ 解析开拓, 记其为 $\Phi^{L}\left(T ; T_{0}, W_{0}\right)$.

定理 1 (解的延拓定理) 设 $\Phi(T)$ 为 一给定解之解析开拓, $\mathrm{D}$ 为其定义域。如果 $\Phi(T)$ 可沿弧线 $L$ 解析开拓以及存在

$$
T_{n} \in L(n-1,2, \cdots, \infty),
$$

使得

$$
\lim _{n \rightarrow \infty} T_{n}-T_{0}, \quad \lim _{n \rightarrow \infty} \Phi^{L}\left(T_{n}\right)=W_{0} .
$$

则有 $T_{0} \in D$.

它王 2(解对初值的连续依赖性定理) 设 $L$ 为 $\mathrm{D}\left(T_{0}, W_{0}\right)$ 中连接 $T_{0}$ 与 $T_{1}$ 的简 单光滑曲线. 则存在 $W_{0}$ 的邻域 $U_{0}$, 使得 对任何 $W \in U_{0}$, 有 $L \subset D_{\left(T_{0}, W\right)}$ 且 $\lim _{W \rightarrow W_{1}} \Phi^{L}\left(T ; T_{0}, W\right)=\Phi^{L}\left(T ; T_{0}, W_{0}\right)$ 对 $T \in L$ 一致成立.
考虑复自治解析系统

$$
\frac{\mathrm{d} W}{\mathrm{~d} T}=F(W), \quad W \in C *,
$$

其中 $\boldsymbol{F}: \boldsymbol{C} \rightarrow \boldsymbol{C}=$ 为解析函数. 简记 $\Phi(T$; $\left.0, W_{0}\right)$ 与 $D\left(0, W_{0}\right)$ 分别为 $\Phi\left(T, W_{0}\right)$ 和 $D\left(W_{0}\right)$.

\section{定义 集合}

$$
\begin{gathered}
\Sigma\left(W_{0}\right)=\left\{W ; W=\Phi\left(T, W_{0}\right),\right. \\
\left.T \in \mathrm{D}\left(W_{0}\right)\right\}
\end{gathered}
$$

称为复解析系统 (2) 过点 $W_{0} \in C^{-}$的相曲 面。

显然, 如果 $W_{0} \in C^{m}$ 为 (2) 式之有限奇 点, 即 $F\left(W_{0}\right)=0$, 则

$$
\Phi\left(T, W_{0}\right)=W_{0}, \quad T \in C^{1},
$$

因而 $\Sigma\left(W_{0}\right)=\left\{W_{0}\right\}$.

命国 1 对 $W_{0}, W_{1} \in C^{m}$, 如果

则 $\Sigma\left(W_{1}\right)=\Sigma\left(W_{0}\right)$.

命西 2 对 $m=1$ 维的方程(2), 设

$$
C_{0}=\left\{W \in C^{1} ; F(W)=0\right\} .
$$

则对任何 $W_{0} \in C \backslash C_{0}, \Sigma\left(W_{0}\right)-C \backslash C_{0}$.

定理 3 设 $\Sigma$ 为(2)之一相曲面. 如果 $W_{0} \in \Sigma$, 则有 $\Sigma \supset \Sigma\left(W_{0}\right)$.

\section{赵晓强}

(中国科学院应用数学研究所, 北京 100080)

\section{随机序列的线性复杂度}

随机序列的线生复杂度尽管也具有随机 性, 但它们的期望值却约为其长度的一半. 并且对任意随机序列, 可至多改变一位使其 线性复杂度达到长度的一半. Rueppel ${ }^{[n]}$ 证 明了长为 $\boldsymbol{n}$ 的二元随机序列线性复杂度的期 望值为

$$
E\left[L\left(S^{n}\right)\right]-\frac{n}{2}+\frac{4 R_{2}(n)}{18}-2^{-*}
$$

$$
\cdot\left(\frac{n}{3}+\frac{2}{9}\right)
$$

其中 $R_{2}(n)$ 是 $n$ 除以 2 后的余数. 本文讨 论 $G F(p)$ ( $p$ 是素数)上的序列. 我们得到 以下结论:

定理 1 长为 $n$ 的任意序列 $S^{n}$ 可 至 多改变一位使其线性复杂度为 $\left[\frac{n+1}{2}\right]$. 